\title{
TRASPOSICIONES: \\ UN ROMANCE EPISTOLAR DE SOR JUANA
}

\author{
POR \\ ROBERTO ECHAVARREN \\ New York University
}

Los romances epistolares ocupan un lugar notable en la producción de Sor Juana. Basta pensar en la considerable serie que escribe a las dos Virreinas, Marquesa de Mancera y Condesa de Galve, o los escritos a otros personajes notables de entre sus amigos, como el Capitán Don Pedro Vélez de la Cadena, su padrino, o el Oidor Don Diego Valverde. También hay romances a personajes que no conocía personalmente, como el Caballero del Perú, que la había felicitado por sus versos, o la Gran Duquesa de Aveyro o el destinatario conjunto denominado «las inimitables Plumas de la Europa».

Queda por explorar este vasto corpus en sus características particulares y en su problemática propia. Lo que aquí me propongo hacer es dar un paso singular leyendo el romance a Don Diego de Valverde, Oidor de Indias.

Como muchos de los romances, éste tiene una extensión apreciable (doscientos doce versos), composición larguísima si se la compara con los catorce versos de un soneto y relativamente modesta si se piensa en los mil de la silva El sueño. Muchos de los romances epistolares de Sor Juana resultan emparentables con la tradición de amor cortés en que el poeta se dirige a su dama (pienso principalmente en los dirigidos a las Virreinas). De un modo más general, los romances epistolares poseen un tono encomiástico de hipérbole platónica hacia el correspondiente.

El romance a Don Diego Valverde tiene por motivo felicitar a dicho Oidor, «ya electo Oidor de Granada [...], por algún posterior ascenso, que impediría más y más su retorno» a México ${ }^{1}$.

El poema, considerado en conjunto, articula un doble movimiento. El primer movimiento es de alejamiento: Don Diego ha sido nombrado

${ }^{1}$ Nota de Alfonso Méndez Plancarte, en Obras completas de Sor Juana Inés de la Cruz, tomo I, Lírica personal (México: Fondo de Cultura Económica, 1951), p. 418 . 
a un puesto lejano. E1 poeta lo felicita, pero no oculta su pesar por esta ratificación de una ausencia. El punto medio del poema, a mi entender, lo constituye la evocación de la figura justiciera del Virrey, que oficia como una bisagra entre el primer movimiento de alejamiento de Don Diego y el segundo movimiento de conclusión del poema, en que el poeta, con motivo de dar nuevas al correspondiente de la situación en México, evoca la figura de la Marquesa o Virreina. A la ausencia de Don Diego se contrapone en la segunda parte del romance la presencia de la Marquesa. Ese doble movimiento construye una exposición platónica del amor a la belleza, según procuraré mostrar a través de la lectura. Esta concepción se articula con una lógica paradójica, es decir, una lógica que niega o relativiza el principio de no-contradicción. La lógica paradójica tiene antecedentes en las formulaciones de Parménides y de Platón, esta última contenida sobre todo en su diálogo Parménides. Aparece como lógica de las figuras retóricas parcialmente en Lo sublime (tradicionalmente atribuido a Longino) y en Agudeza y arte de ingenio de Gracián.

La lógica paradójica o antitética del concepto gracianesco es el vehículo dialéctico con el cual el poema construye una concepción platónica del amor a la belleza a partir de las circunstancias que motivan el romance epistolar.

La exaltación de Don Diego a su nuevo cargo es directamente proporcional a su mayor alejamiento: "Cuanto os miro más alto / tanto estáis de mí más lejos.» De ahí la ambivalencia de sentimientos del poeta ante la nueva promoción: «Así yo, combatida / de tan contrarios afectos / como el gusto que lográis / y la pena de perderos, / en dos mitades el alma / festiva y llorosa a un tiempo, / mi muerta esperanza lloro / y vuestras dichas celebro.» La ambivalencia de sentimientos frente a la exaltación y lejanía de Don Diego es lo que justifica la lógica paradójica o antitética del concepto, que culmina en la conclusión del siguiente símil: «¿No habéis visto, cuando muere / un Monarca, que su Reino / hace exequias al Difunto, / y fiestas al Heredero, / juntando a un tiempo, leal, / los dos distantes extremos / de aclamaciones del Vivo / con los sollozos del Muerto, / en que tan equivocados / al pesar y al gusto vemos, / que es todo llantos el gusto / y el pesar todo festejos?» La equivocación o mediación de los sentimientos corresponde, como he dicho, con la exaltación y lejanía de Don Diego, pero aún hay más: la situación es el motivo que sirve para revelar la distinción, y aun oposición, en la condición humana entre amor y contento. El nombramiento de Don Diego es ocasión que revela esa verdad fundamental: «Una cosa es el amor / y otra cosa es el contento. / Que bien veis que son dos cau- 
sas / muy distintas, y que a un tiempo / el amor puede ir a más / y el gusto puede ir a menos.» Es precisamente la dicotomía entre amor y contento lo que da a la experiencia amorosa su carácter paradójico: cuanto más se exalta el amor tanto más imposible resulta equipararlo con el contento, el gusto o la satisfacción. Si el objeto del amor no es el objeto de la satisfacción, o mejor, si el objeto del amor es una finalidad de satisfacción imposible (en este caso, la reunión con Don Diego), el amor será tanto más auténtico cuanto francamente imposible sea su objeto. Por eso la experiencia auténtica del amor implica la equivocación o mediación de los sentimientos ( festejos»), es decir, el acercamiento o coincidencia de los contrarios («juntando a un tiempo, leal, / los dos distantes extremos»).

El alejamiento de Don Diego es ocasión, como dije, de una puesta en juego del Eros platónico. La equivocación o mediación de los contrarios a través del juego dialéctico del concepto eleva al poeta a una lúcida experiencia: «Bien sabéis que son / tan nobles mis pensamientos, / que pretendo sólo el lauro / de que ninguno pretendo. / Y también sabéis, que como / es mi amor de entendimiento, / no ha menester de la vista / materiales alimentos, / pues radicando en el alma, / independiente y exento, / desprecia de los sentidos / el inútil ministerio.» El amor que no tiene por finalidad el premio de una gratificación sensible se alimenta de un objeto imposible y se sostiene en la actividad intelectual.

Para ratificar el parentesco entre esta concepción y la platónica del amor basta recordar algunos pasajes del discurso de Diótima en $E l$ banquete. $\mathrm{El}$ «amor de entendimiento» en el romance epistolar que comento sería al segundo paso en la escala ascendente del amor tal como lo concibe Diótima. Los hombres se acercan a la belleza amando primero los cuerpos individuales y visibles, y más tarde, según un proceso de ascesis, amando «las normas de conducta y [...] las leyes», objeto no ya de los sentidos, sino del entendimiento ${ }^{2}$. Quien ha sabido considerar la belleza generalizada que corresponde al ejercicio del pensamiento llegará «a percibir» todo lo que «está unido por parentesco a sí mismo», lo que constituye el «inmenso mar de la belleza». Frente a tan vasto panorama, el iniciado se dará cuenta de que, relativamente a él, «la belleza del cuerpo es algo de escasa importancia». El «amor de entendimiento» en el romance prescinde, en lo que cabe, del inútil ministerio de los sentidos.

${ }^{2}$ Esta y las otras citas de El banquete vienen de Platón, Obras completas, traducción del griego, preámbulo y notas de María Araújo y otros (Madrid: Aguilar, 1966, 1969), pp. 588-589. 
Que el «amor de entendimiento» sea auténtico amor no le quita el sufrimiento o la dificultad de una privación, ya que «una cosa es el amor / y otra cosa es el contento». La privación de la gratificación de los sentidos establece, como ya he sugerido, el primer movimiento del poema: se abre el poeta a la contemplación desgarrada del amor: amor como privación (del correspondiente Don Diego). Pero tal privación exulta con el ascenso de Don Diego. La experiencia del amor consiste en «carecer de vos, / atenta a vuestros aumentos».

Diótima traza el camino del aumento del amor por escalas hasta una culminación momentánea, momento en que el iniciado, «acercándose ya al grado supremo de iniciación en el amor, adquirirá de repente la visión de algo que por naturaleza es admirablemente bello, aquello precisamente, Sócrates, por cuya causa tuvieron lugar todas las fatigas anteriores». El camino ha tenido fatigas, privación, esfuerzo; pero esto ha sido en aras de un aumento, que, sin embargo, no es sino repentino («adquirirá de repente la visión de algo...»). El nombramiento a un puesto (de Don Diego) equivale a su ratificación como Señor o verdadero objeto de amor, y no de contento, a los ojos del poeta. Los aumentos de Don Diego son ocasión para que el poeta descubra o recuerde su amor desgarrado por la separación. Lo que el amor entrega al poeta no es un galardón, porque «pretendo sólo el lauro / de que ninguno pretendo». La dialéctica amorosa quita paradójicamente aquello mismo que propone como objeto; en este caso, Don Diego, que asciende o es ratificado como Señor.

Para Diótima, el «grado supremo de iniciación en el amor» proporciona una visión momentánea, repentina: «Adquirirá de repente la visión de algo que por naturaleza es admirablemente bello.» Esta visión resulta anticipada en el discurso como aquello que será su culminación: de este modo, la visión de la belleza alimenta el discurso, lo hace engendrar, lo aumenta. Lo «admirablemente bello» resulta, pues, una carencia de objeto, una anticipación de máxima intensidad momentánea. En el discurso de Diótima, el lugar de lo bello anticipado es ocupado, obturado, en la frase que cité por un nombre propio que pertenece al destinatario de su discurso, Sócrates («adquirirá de repente la visión de algo que por naturaleza es admirablemente bello, aquello precisamente, Sócrates, por cuya causa tuvieron lugar todas las fatigas anteriores»).

En el romance, Don Diego, el destinatario, se ve nombrado en el lugar del Señor, en el lugar de algo que sería el objeto imposible del amor. En el movimiento de apertura del poema, el poeta se abre a la iniciación en el amor de un objeto que se consagra al apartarse. Ese objeto es nombrado Don Diego, el correspondiente o destinatario del romance 
epistolar. Sócrates, en la frase de Diótima, y Don Diego, en el romance epistolar, ocupan el lugar, vienen a nombrarse o a caer en el lugar de «algo que por naturaleza es admirablemente bello». La reputación, podría decirse, de lo bello se basa en el nombre que lo consagra como objeto imposible de un afecto.

Siendo lo bello finalidad suprema del discurso - de Diótima, del romance epistolar-, ¿a quién ha de dirigirse el mensaje o la misiva sino al causante del discurso? El destinatario no puede ser otro que el objeto imposible del amor. El romance vale para la ocasión del ascenso de Don Diego, que es ocasión de un encuentro con lo bello.

Este encuentro momentáneo en la iniciación del amor resulta ser, sin embargo, según Diótima, un encuentro con lo que «existe siempre, no nace ni muere, no crece ni decrece, que en segundo lugar no es bello por un lado y feo por otro, ni tampoco unas veces bello y otras no, ni bello en un respecto y feo en el otro, ni aquí bello y alli feo, de tal modo que sea para unos bello y para otros feo». Sin contradicción no se puede pensar la identidad del uno. Lo bello, «algo que por naturaleza es admirablemente bello», es uno consigo mismo, pero no puede llegar a contemplarse sino a través de una mediación contradictoria en la situación precaria del discurso o epístola. La paradoja dialéctica en Platón resulta aquí en «adquirir de repente la visión» de algo que, como lo bello, «existe siempre, no nace ni muere, no crece ni decrece». En el romance epistolar, el uno, Don Diego, privado o a distancia, es contemplado a través de la mediación contradictoria del concepto gracianesco: «Carezcan de vos mis ojos, / si ha de ser para bien vuestro; / que antepone mi fineza / el veros feliz, al veros» (yo subrayo). La visión repentina de lo que "existe siempre» equipara la privación con la vista. La contradicción se instala en el núcleo de todo lo que es visión o sentido.

El «carezcan de vos mis ojos» del romance consagra a Don Diego como el objeto imposible del amor. En El banquete, según el discurso de Diótima sobre el amor, lo bello en sí o lo bello por excelencia, objeto último del iniciado en el amor, no aparecerá «como un rostro, unas manos, ni ninguna otra cosa de las que participa el cuerpo». La belleza como tal se sustrae a la visión sensible. Pero, en rigor, se sustrae también a la visión o representación intelectual, ya que tampoco aparecerá «ni como un razonamiento ni como un conocimiento». En el romance, el amor a Don Diego pone de manifiesto su carencia. El objeto del amor es una privación tanto sensible como inteligible, y, sin embargo, es a la luz de esa privación que nace el discurso, la carta de amor o romance epistolar. También Diótima señala que, aunque lo bello en sí se sustrae no sólo a lo sensible, sino también al pensamiento, es, sin embargo, la 
consideración de esta carencia lo que engendra discursos y pensamientos.

En un símil alegórico que toma veinte versos del poema, Don Diego es comparado con el sol, y la distancia entre el Oidor y el poeta con la distancia entre el sol y la tierra, mientras que los rayos del sol se equiparan al influjo del Don Diego ausente sobre el poeta en tanto causa de su amor:

Mucho dista el Sol luciente / de la tierra, y no por eso / dejan en ella sus rayos / de producir sus efectos. / Por más que doblen distancia / esos claros once espejos, / idejan de imperar los Astros / en los sublunares cuerpos? / No; luego menos, Señor, / podrán impedir quereros / golfos de tierra envidiosos, / muros de mar interpuestos, / pues mayor que su distancia / es, para obrar en mi pecho, / la actividad de la Esfera / de vuestros merecimientos.

La distancia horizontal entre dos puntos de la tierra se vuelve, a través del símil alegórico, una distancia o medida cósmica. La relación amorosa con Don Diego es comparada con una relación vertical entre los Astros y la tierra. Este símil alegórico es reminiscente del viaje o ascenso alegórico del alma hasta el confín de las esferas celestes en el poema más considerable de Sor Juana, la silva $E l$ sueño. El símil alegórico del romance está construido como un silogismo: la mayor distancia, o distancia vertical, entre el sol y la tierra no impide que los rayos del sol la atraviesen para ejercer sus efectos en la tierra, ni la distancia entre los astros en general y la tierra impide que éstos gobiernen a los cuerpos terrestres o sublunares: La distancia menor, o distancia horizontal, no impedirá, por tanto, que Don Diego incite el amor del poeta. Este símil alegórico y silogístico, que además incluye una pregunta retórica («idejan de imperar los Astros / en los sublunares cuerpos?»), pone en juego la mayor distancia para negar la distancia. En tanto alegoría, ofrece al amor una distancia o medida cósmica: «Mayor que su distancia / es, para obrar en mi pecho, / la actividad de la Esfera / de vuestros merecimientos.» Según la alegoría, Don Diego está tan distante como los astros situados en sus respectivas esferas celestes (los «claros once espejos»). Se trata de una medida cósmica o absoluta. La distancia entre los amantes es equivalente a la mayor distancia, pero esa distancia es anulada al obrar el objeto distante o ausente sobre el pecho amante del poeta. La distancia o separación entre Don Diego y el poeta impide el contento o la satisfacción, a la vez que da la medida cósmica de un amor que supera la distancia.

El cosmos, término del símil alegórico, es la medida o distancia que separa los dos polos de la relación amorosa. Arriba se sitúan los cuatro 
términos escritos con mayúscula: Sol, Astros, Señor, Esfera. Abajo, tanto los cuerpos sublunares o terrestres como el pecho del poeta. Según el tratado De lo sublime (atribuido tradicionalmente a Longino), este símil sería calificado de sublime, ya que en él el poeta amante «mide su salto» en relación al objeto de su amor «con una medida cósmica». Es precisamente esta medida cósmica o máxima que es anulada por la desmesura de su amor. Según Longino, el pasaje que es sublime logra representar, dar una idea, de algo que resulta en cuanto tal irrepresentable, la desmesura de un deseo. La dialéctica paradójica articula la mediación discursiva que se refiere al objeto imposible del auténtico amor o «amor de entendimiento».

El conflicto entre la desmesura del amor y la limitación, esta vez del verso, es la cuestión que se plantea en el comienzo mismo del romance:

Señor Don Diego Valverde / (y no os parezca despego / no decir mío, que fue / porque no cupo en el verso, / aunque su estrechez ceñida / poco embaraza mi afecto, / pues lo que no cabe en él / sabéis que cabe en mi pecho). / Y supuesto, Señor mío, / bien que el serlo no es supuesto, / porque siempre que os declino / es por meus, mea, meum, / vamos a lo principal, / aunque por difícil tengo / apartarme de un cariño / por acercarme a un respeto.

La estrechez del verso contrasta con la amplitud del pecho del poeta, ya que en ese pecho cabe el amor desmesurado. Sin embargo, el conflicto entre la medida limitada y la desmesura es lo que lleva al verso a extenderse en discurso. Es decir, que ya que no cabía el mío en el primer verso, se le da lugar en el resto del poema. El discurso crece a partir de un conflicto entre mesura y desmesura y prosigue como una declinación del mio («siempre que os declino / es por meus, mea, meum»). La declinación del mío puede leerse en su revés, que sería el clinamen, a lo largo del poema, de su objeto imposible ( os declino», yo subrayo). El objeto imposible es el correlato objetivo del mio en la polaridad amorosa. El sujeto (el poeta) escribe su poema atento a los aumentos de su correlato objetivo, el objeto imposible de amor (con «carecer de vos, / atenta a vuestros aumentos»).

En el desarrollo del poema, si no en el primer verso, el mío encuentra su puesto. Pero el amor del mío carece de aquello mismo que nombra como mío, de Don Diego, su correlato objetivo. El objeto del amor es la causa de la experiencia de algo mío para el poeta. El discurso poético se vuelve el puesto del mio en la medida en que éste refiera a su correlato objetivo, causa del amor y causa del discurso.

Nombrar lo mío es nombrar un objeto carente, que obra a distancia 
(una medida cósmica) para activar al mío o al amor de su pecho, y al obrar así, superar o suspender la distancia. Si el mío no encuentra su puesto en el primer verso, lo encuentra, como dije, en el resto del poema, declinación o derivación del mío. Pero el puesto del mío, el poema, designa o refiere una carencia. ¿Cuál es entonces el puesto del mío? A la vez el discurso poético y el lugar distante donde se encuentra su objeto imposible, el ausentado Don Diego. El mio tiene puesto (el discurso en el sentido diacrónico de enunciación y en el sentido sincrónico de enunciado) y a la vez carece de puesto (ya que está desubicado en relación a su correlato objetivo distante o ausente).

La posición del mío frente a un objeto carente de representación (ausente a los sentidos y evocado a distancia por el discurso) implica una suspensión o superación del narcisismo, conflicto doloroso para el poeta, ya que su amor auténtico hacia un objeto imposible impide el contento de una gratificación. Pensar a través de las imágenes (alegoría, medida cósmica) lo que carece de imagen supone siempre, entre el mio y el objeto imposible, una mediación contradictoria. Don Diego, que dadas las circunstancias es el nombre de ese objeto imposible en el poema, corresponde al mío (Señor mío) no, pues, en una relación de apropiación (ya que el poeta no puede apropiarse de Don Diego, carece de él), sino en una relación de servidumbre (el poeta está sujeto amorosamente a Don Diego).

Ya que lo que se discute al comienzo del poema es tanto el lugar como la posición del mío (que no cabe en el primer verso), con respecto al poema, de un lado, y con respecto al Señor, de otro, cabe leer a la luz de esta cuestión los versos siguientes (que ya he citado): «Y supuesto, Señor mío, / bien que el serlo no es supuesto, / porque siempre que os declino / es por meus, mea, meum.» El Señor, como mío, resulta un a priori del discurso, su condición o causa, su sostén. Este es el sentido filosófico de supuesto según el Diccionario de Autoridades: «Término de filosofía, y usado como sustantivo, es la individualidad de la sustancia completa, e incomunicable. Llámase así porque queda puesta debajo de todos los accidentes.» Suponer, o poner debajo, implica una precedencia lógica del lugar del Señor como supuesto, o lugar puesto de antemano y por debajo como sostén, causa, o condición del discurso. Pero a la vez el lugar del Señor es la finalidad del discurso o epístola amorosa y resulta un a posteriori según el espectro de la articulación sintagmática de las declinaciones. De ahí que se diga «bien que el serlo no es supuesto». El lugar del Señor es declinado en el discurso según las declinaciones del mío, aunque sin pasar a predicado, manteniéndose siempre en el nominativo: meus, el mío; mea, la mía; meum, lo mío. 
La descolocación del lugar del Señor con respecto al puesto del poeta hace que, en el nivel del contenido manifiesto del discurso, la suposición resulte equivocada («bien que el serlo no es supuesto») al menos en cuanto al género del Señor, que condiciona al mío no como elemento particular, sino como el conjunto de su referencia (a la vez masculino, femenino y neutro). Al ser causa o antecedente absoluto del discurso y ser su finalidad como objeto imposible, el Señor es nombrado o declinado en las incidencias concretas de los diferentes géneros, pasando en cada caso de supuesto o implícito a manifiesto, a la vez que cada uno de los casos o manifestaciones alude al Señor como categoría de conjunto virtual o espectro absoluto de las posibilidades concretas de designación.

Si Don Diego, a lo largo del romance, y con motivo de su ascenso, queda colocado del costado del bien, de la felicidad, del aumento, el poeta, por su parte, queda colocado del costado del pésame, de la queja, del pesar, de la carencia de un pláceme, de la pena, del llanto, de la parte perdidosa, del menos, del mal. En cuanto bien, felicidad, alegría, aumento, Don Diego resulta irrevocablemente separado, diverso, en relación al poeta. La estrechez del primer verso, como la estrechez de su corazón, no le permite colocar el mio al costado del nombre de Don Diego. A lo largo del poema, una consideración de la alegría y el aumento de Don Diego va ensanchando al corazón del poeta. A través de un ejercicio de pensamiento y de escritura (discurso poemático epistolar), el gozo de Don Diego va ejerciendo su influjo en el pecho del poeta enamorado, va obrando en ese pecho una representación de su gozo, mediada, sin embargo, por el pesar de una representación, por el mal y la pérdida de poner un gozo, el de Don Diego, en la escritura situada del lado de la carencia, del mal, de la disminución.

El costado del pensamiento y de la escritura es el costado del trabajo y de la angustia. En otro romance, "Finjamos que soy feliz», el poeta llama al pensamiento y la escritura un "pésimo ejercicio», un «duro afán pesado», pues «cuanto añado al discurso, / tanto le usurpo a los años». El pensamiento y la escritura se justifican, según ese romance, meramente como un ejercicio de ascesis, que «a los hijos de los hombres / dio Dios para ejercitarlos». El pensamiento y la escritura (de los hombres) se encuentran situados del lado del trabajo, del esfuerzo, de la pena, de la angustia. El otro lado es en rigor costado de Dios. De ese lado se sitúa un goce que los hombres solamente pueden considerar en su duro ejercicio amoroso que sería una vida de ascesis dedicada al pensamiento y la escritura.

Don Diego, en el romance epistolar, ocupa, especialmente a través 
del símil alegórico que da una medida cósmica, el lugar de Dios. Es cierto que su felicidad, su alegría, son mundanas, ya que el poema tiene por ocasión felicitarle por un ascenso en el escalafón jurídico de la administración colonial. Pero esta ocasión es apenas el punto de partida, una distribución contingente de la situación (ascenso y alejamiento de la Corte del Virrey de México). Este azar permite al poeta redefinir su situación, revivir a través de circunstancias concretas la verdad de una experiencia amorosa. El romance a Don Diego repite, para el poeta, una experiencia que es la misma (de otras ocasiones), ya que consiste en la aplicación de una ley (simbólica y real) que sitúa al objeto de amor del costado de un goce imposible o divino.

El primer movimiento del poema establece la separación entre el poeta y el objeto de su amor (Don Diego), que resulta también separación de alegría por un lado (Don Diego) y pesar por otro (el poeta). En relación al costado de Don Diego, no cabe el mío del poeta. Cuando el poeta logra integrar el mío en el desarrollo subsiguiente del poema, se trata de un mío alienado, perdido para el poeta del lado inaccesible de Don Diego.

Al final de este primer movimiento del poema el poeta envía saludos a dos miembros de la familia inmediata de Don Diego:

A mi Señora Doña Ana, / vuestro digno hermoso empleo, / dad de mi parte un abrazo, / y cobrádselo en lo mesmo; / que si acepta la libranza, / no hay duda que quedaremos, / yo sin la deuda, gustoso / vos, y todos muy contentos. / Y a mi Señor Don Gregorio, / le diréis que en Dios espero / verlo Magno, cuando no / Taumaturgo Nacianceno.

La familia inmediata de Don Diego merece del poeta, en la persona de la esposa, Doña Ana, y del hijo, Don Gregorio, el empleo del $m i$ por parte del poeta. En estos dos casos, según se ve en los versos citados, el $m i$ sí llega a caber en los respectivos versos en que se nombra a estos personajes. El pecho del poeta y su epístola se han ensanchado lo suficiente, a través de una contemplación amorosa del objeto carente (Don Diego), como para darle cabida. Pero el $m i$ del poeta se refiere a personajes que, lo mismo que Don Diego, están situados en la ausencia, del lado del goce ajeno al poeta, quien, por su parte, está sumido en el mal de su pesado ejercicio, de sus trabajos sin lauro, y de la falta de contento. $\mathrm{Y}$, sin embargo, aquí, por primera vez en el poema, se concibe la posibilidad de un contento del lado de acá, del lado del poeta: si Don Diego le da a su esposa Doña Ana un abrazo de parte del poeta y si se lo cobra «en lo mesmo», es decir, si los esposos, del lado de allá, en la 
ausencia, se abrazan entre ellos, pero en nombre del poeta, ese hecho a control remoto o a distancia tendrá repercusiones del lado de acá, del lado del poeta, ya que entonces "no hay duda que quedaremos, / yo sin la deuda, gustoso / vos, y todos muy contentos» (yo subrayo). E1 poeta, al escribir el romance epistolar, está pagando a Don Diego la deuda de darle un pláceme o felicitación por el ascenso. Ese pago redunda en el mayor gusto para Don Diego, quien gana con el nuevo nombramiento; su ganancia resulta consagrada o celebrada por el romance epistolar. El romance no inventa la ganancia o aumento de Don Diego, sino que la reconoce, la considera amorosamente. $\mathrm{Y}$ al hacerlo, la instituye para el poeta en su discurso, ya que, a través del poema, el gusto o goce de Don Diego resulta en una efusión a control remoto: el poeta paga su deuda amorosa con una petición: que los esposos se abracen. El poeta paga su deuda en trabajos, redacta la carta o petitorio del abrazo; mientras que del otro 1ado, los esposos abonan conjeturalmente esa orden de pago o «libranza» con un abrazo que se dan mutuamente. Ellos pagan la libranza en gozo con una efusión para con ellos del lado de allá, y de esta manera incluyen al poeta in absentia como un tercero participante vicariamente en ese gozo («quedaremos [...] todos muy contentos»). Resulta entonces que el poeta, que por un lado carece de contento, participa vicariamente en el contento de los esposos ausentes. Es la instalación de una familia del lado del Señor lo que permite al poeta el gozo. Los esposos, en el abrazo, son una díada que se unifica. Pero a la vez la esposa, Doña Ana, y el hijo, Don Gregorio, son nombrados uno detrás del otro, juntos, en ese lugar ausente que es el que habita y define Don Diego. Si el esposo y la esposa forman una díada en el lugar ausente, la esposa y el hijo forman otra díada; y el esposo, la esposa y el hijo, una tríada. El cuarto término es el poeta, que está del lado del trabajo, no del goce. Pero, en el momento de la efusión, el hijo pasa a representar al poeta del lado de allá, como tercero participante en el gozo de los esposos. Don Diego, Doña Ana y el poeta quedarán todos a tres muy contentos en caso de verificación del abrazo, pago de la orden de pago o libranza que emite el poeta con su epístola (que a su vez paga la deuda del pláceme, felicitación o celebración que consagra, e instituye para el poeta el aumento de Don Diego). El poeta, pues, se desdobla, en el poema, en alguien sin contento del lado del trabajo, y en alguien participante del contento del lado del goce del Señor. Del lado de allá encuentra conjeturalmente un representante en el personaje de Don Gregorio. He dicho que Don Diego, en el romance epistolar, ocupa, especialmente a través del símil alegórico que da una medida cósmica, el lugar de Dios. Al referirse a Don Gregorio, el poeta indica que espera verlo aumentado o 
Magno o con poder de curar en Dios, según el poder de Dios: «Y a mi señor Don Gregorio, / le diréis que en Dios espero / verlo Magno, cuando no / Taumaturgo Nacianceno». Don Gregorio, que, según el verso, es un señor con minúscula, habita conjeturalmente, sin embargo, del lado de la mayúscula, del lado de Dios. Don Gregorio, en Dios, representa al poeta como participante virtual o conjetural del gozo de ese lado. En el verso inmediatamente anterior a aquel en que se lo nombra, el poeta considera la eventualidad conjetural de una participación en el contento de los esposos ("y todos muy contentos»). Que Don Gregorio represente efectivamente al poeta de ese lado constituye la esperanza del poeta de llegar a verlo Magno (aumentado) o poderoso (Taumaturgo) en Dios.

$\mathrm{Y}$ es precisamente esa posibilidad conjetural lo que se efectúa según el segundo movimiento del poema. Hasta después de los saludos a la familia de Don Diego, el romance menciona sólo a personajes que se encuentran del lado de allá, es decir, ausentes. Pero entonces se hace mención de dos personajes que están del lado de acá, es decir, del lado del poeta. Doña Ana y Don Gregorio viven con el destinatario (ausente) de la epístola. Los Virreyes, mencionados a continuación, viven en el lugar del poeta, en México: «Las cosas de por acá / se están así, que es el Reino / malo para Atica, porque / no tiene nada de nuevo. / [...] / Sólo de Sus Excelencias / hay mucho que decir; pero / son Sus Excelencias tales, / que no hay qué decir en esto.» Con estos versos se ha efectuado un pasaje de las figuras o personajes mentados del lado de allá al lado de acá. A la mención de la díada de Doña Ana y Don Gregorio sigue inmediatamente la entrada de la pareja de "Sus Excelencias», el Virrey y la Virreina, Marqueses de la Laguna, que viven y gobiernan "por acá». La posibilidad de contento para el poeta según su participación en el abrazo conjetural que en cumplimiento de su orden de pago se darían Don Diego y Doña Ana del lado de allá redunda en un pasaje de la visión amorosa al lado de acá, en la figura, como se verá, de la Marquesa de la Laguna.

El discurso, en este punto de la composición, vuelve el gozo, por así decir, reversible, por un acto de justicia que articula el movimiento del poema. El amor por el Señor ausente de un poeta descontento, sin satisfacción o lauro, se sostiene en la consideración de un aumento o gozo del Señor, quien, por excelencia, es el lugar del gusto, del contento. El gusto, el goce o el contento cabales son representados, del lado del Señor, como la efusión de una díada: el abrazo mutuo de Don Diego y Doña Ana. Es un abrazo, por así decir, de Dios con Dios. O sea, que se mantiene del lado de allá, que es el lado del gozo de Dios. Se mantiene, el abrazo, encerrado consigo mismo. Sin embargo, a través de la epístola, 
que instituye, para el poeta, el aumento de Don Diego, se formula una libranza u orden de pago para que los esposos, del lado de allá, se den ese abrazo. Y ese trabajo, ese ejercicio de escritura, instituye, para el poeta, la eventualidad conjetural de una participación vicaria y además mediata (a distancia y a través de un representante en ese otro lado, Don Gregorio) en el contento de una efusión. El punto de pasaje a las "cosas de por acá», el punto de pasaje entre la mención de Doña Ana y Don Gregorio y la de Sus Excelencias, es el momento del poema en que la efectuación conjetural de la participación en el goce se vuelve certidumbre (momentánea).

El primer movimiento del poema (versos 1 a 148) expone el «amor de entendimiento» del poeta por su Señor ausente, Don Diego. Causa absoluta y objeto imposible de ese amor, Don Diego es único, es el uno cuya ausencia determina la privación del poeta. Para que el aumento, el gusto, la ganancia, el contento de ese uno se transmitan al poeta a distancia, le es necesario al poeta representar al uno como la unión de dos, y a su contento como una efusión que consiste en un abrazo entre esposos. Esos dos que son uno, que se hacen uno en la efusión, dan lugar a su vez a un tercero, o hijo, que en Dios o en el lugar del gozo de Dios participa de él: Don Gregorio, que será eventualmente Magno o Taumaturgo.

Pero esta operación del discurso, instalar la representación del gozo en el lugar del Señor, equivale a instalar la multiplicidad en el lugar de la unidad. El pensamiento, en tanto productivo, es un proceso dialéctico que trasvasa los contenidos de uno y otro lado, aunque mantiene la diferencia. El poeta nunca deviene el Señor, sino que puede llegar a ser Magno o Taumaturgo en Dios. El sujeto del gozo en el poema, representado por Don Gregorio, juega en el dispositivo dialéctico como la resultante de un proceso de mediación que implica una causa absoluta y un objeto imposible de gozo (Don Diego) y un sujeto de privación y pesar en el trabajo, el poeta. Doña Ana, de un lado, y la Marquesa de la Laguna, por otro, instalan la dualidad en la representación del gozo. La unión de dos en uno, la efusión del abrazo, operan la representación del gozo, es decir, lo mediatizan. El gozo participado o mediatizado dialécticamente es el efecto del discurso o romance epistolar. Esta participación en el gozo es un acto de justicia poética. La figura del Oidor, Don Diego, representa a la justicia en tanto ausente; el Virrey, Marqués de la Laguna, representa, como se verá, a la justicia en acto.

El lado de acá, el Reino (lugar del poeta), «no tiene nada de nuevo». La única novedad propiamente dicha del poema la constituye el nombramiento de Don Diego, que es un suceso ausente, que ocurre del otro 
lado. De acá no hay noticias: «no hay qué noticiaros, / porque es ya todo tan viejo, / que el nihil sub sole novum / tienen todos en proverbio». Lo que ocurre, ocurre del lado de allá, y es el nombramiento o aumento de Don Diego, y eventualmente, en cumplimiento de la orden de pago o libranza de la epístola, la efusión o el abrazo entre los esposos. La repercusión del abrazo del lado de acá, la participación del poeta en el gozo del abrazo, vendría a ser el premio, o lauro, que el Señor otorgaría en un acto de soberana justicia, y precisamente porque el poeta ha renunciado de antemano a un beneficio o satisfacción directa («pretendo sólo el lauro / de que ninguno pretendo»). Los beneficiarios directos o inmediatos del abrazo son los esposos. El amor del poeta por Don Diego ausente es "amor de entendimiento» distinto del contento, que prescinde de los «materiales alimentos» y «desprecia de los sentidos / el inútil ministerio». Al renunciar a todo contento o satisfacción inmediatos, el contento sólo podrá llegar al poeta mediatizado, a través de la redacción de la epístola, que intima una orden de pago indirecto.

El amor del poeta está "radicado en el alma». El amor es un ejercicio, prueba, o tormento del alma: "vuestra ausencia el alma, / con dos distintos respectos, / la ignora, cuanto al olvido, / la sabe, cuanto al tormento». El beneficio indirecto que recibiría el poeta del abrazo de los esposos sería, de parte del Señor, efecto de un acto de justicia o reconocimiento en favor de un auténtico «amor de entendimiento» - «radicado en el alma»- del poeta. La renuncia a los «materiales alimentos», al «ministerio» de los «sentidos», es la condición que autentica el amor del alma. La separación entre amor y contento equivale a la distinción entre alma y cuerpo. La experiencia real del amor que carece de gratificación sensible opera una separación ficticia entre cuerpo y alma. Al leer la epístola, el Señor, gracias a la separación establecida entre amor y contento, podrá apreciar la autenticidad del amor del poeta: «Carecer por vos de todo, / no hubiera sido en mi afecto / fineza, que aun lo insensible / lo hace, por irse a su centro. / Pero carecer de vos, / atenta a vuestros aumentos, / digan si ha sido fineza / vuestras prendas y mi aprecio». El «amor de entendimiento» por el Señor implica no sólo la renuncia a la gratificación sensible, sino también la carencia del Señor al cual se ama, en tanto pensar en él no conjura su ausencia. El amor tiene un objeto imposible, pero real. El Señor, en un acto de soberana justicia, puede apreciar el amor desinteresado, a través de la lectura de la epístola, de un alma desnuda o purificada. La efusión de los esposos entre sí repercutirá en la participación mediata del poeta en su gozo. Esta mediación lógico-discursiva puede alegorizarse al ser representada como antes y después, como la sucesión de dos momentos separados uno 
del otro: vida terrenal y vida después de la muerte. El juicio de Dios concierne al alma y se lleva a cabo, según la alegoría de sucesión, después de la muerte, es decir, estando el alma separada del cuerpo. El amor del alma es desinteresado en tanto no aspira a ningún premio o lauro en esta vida, sino después de la muerte.

La profesión de Don Diego, Oidor, consiste en hacer justicia. La profesión de Su Excelencia el Virrey es también la de gobernar o hacer justicia. Mientras la justicia del Oidor se ejerce en un lugar ausente, la justicia del Virrey resulta alegorizada como justicia con respecto al alma después de la muerte: "Tan innato en Su Excelencia / es el juzgar bien y recto, / que parece que nació / a ser Juez, hecho y derecho. / Radamanto con Eaco / y Minos, si a su gobierno / se comparan, pueden irse / a sentenciar al Infierno». Según la alegoría que narra Sócrates al final del Gorgias, estos tres jueces son el tribunal que toda alma encontrará después de la muerte. Estos jueces no se engañan porque el alma, ya separada del cuerpo, aparecerá ante ellos sin ese vestido que la oculta en vida. El juicio de Su Excelencia el Virrey resulta hiperbólicamente superior al de estos excelentes jueces. En cumplimiento de un acto de justicia asignado primeramente al ausente Don Diego y a partir de este momento al presente Virrey, el poeta logra un contento paradójico, es decir, mediatizado dialécticamente en la epístola.

Por un acto de justicia del Señor le es otorgado al poeta un contento paradójico, una visión amorosa negativizada o indirecta, una determinación conjetural de lo real, representación dialéctica o negativizada de un goce absoluto del Señor. Al ser comparado hiperbólicamente con Radamanto, Eaco y Minos, Su Excelencia el Virrey se convierte en juez de almas alegóricamente separadas del cuerpo. Al comparecer frente al Virrey, el poeta entra alegóricamente en la muerte, y obtiene, dentro de lo que cabe a los humanos, por un acto de justicia, la participación en el goce del Señor. Según la alegoría del juicio final implicada por la comparación hiperbólica, la ausencia del Señor (Don Diego) sólo se trueca en presencia (del Virrey) después de la muerte. Pero la muerte alegórica representa, en vida, una doble renuncia que debe hacerse verdadera antes que el poeta alcance su paradójico contento: renuncia a la gratificación sensible y a cualquier bien en general que no sea el Señor, y renuncia al Señor o reconocimiento de su ausencia. A partir de esta renuncia o muerte alegórica, el poeta comparecerá a la presencia del Señor para ser juzgado.

$\mathrm{Y}$, según el acto de justicia del Señor, logra, en el segundo movimiento de la epístola, la visión de la gloria en la figura de la Virreina, Marquesa de la Laguna: «En fin, por hablar de Gloria / os la nombré 
a lo postrero; / que es pronóstico a mi dicha / ser mi fin su hermoso Cielo». O bien «la señal por donde se conjetura o adivina alguna cosa futura», o bien «predicción o adivinación de cosas futuras, hechas por la observación de algunas señales que se han visto» (Diccionario de Autoridades), el pronóstico, en los versos citados, define el segundo movimiento del romance epistolar. En la primera parte se habla de un pláce$m e$ (amoroso) dado sin contento (debido a la ausencia del objeto amoroso), que termina en una libranza u orden de pago indirecto (efusión amorosa entre los esposos). El pago conjetural de esa orden por parte del Señor es figurada como una díada (los esposos) que se unifica (abraza), dando lugar a un testigo, el hijo, Don Gregorio, que participa del gozo en Dios. Esta conjetura con respecto a un lugar ausente puede ser ratificada por el Señor, que por un acto de justicia permite al poeta participar en su gozo. Ocurre entonces el pronóstico, la anticipación de la gloria, la cual, en el romance, está figurada por la Virreina, Marquesa de la Laguna, a la cual se dedican los cuarenta últimos versos del poema.

Su aparición del lado de acá, la visión de la que participa el poeta, de los atractivos de la Marquesa, anticipa la gloria como finalidad absoluta del discurso epistolar («es pronóstico a mi dicha / ser mi fin su hermoso Cielo»). El fin de la obra poética se distingue con respecto a su forma. El montaje del concepto gracianesco, paradójico, cuyo desarrollo dialéctico es el poema, tiene un fin exterior a él en cuanto resulta aconceptual: el fin es una totalidad que escapa al concepto, mientras el poema es la anticipación de ese fin que se escapa al final.

Pero mientras dura, confirma un acto de justicia que viene de un Señor que está en otro lugar. El segundo movimiento del poema efectúa esa justicia en la visión anticipatoria de la gloria, que ocurre, en rigor, después de la muerte, habiendo juzgado al alma un juez excelente, hiperbólicamente superior a los jueces mejores póstumos Radamanto, Eaco y Minos. Muerto, el poeta renace a la gloria nombrada a lo postrero («en fin, por hablar de Gloria, / os la nombré a lo postrero»). En el discurso, el poeta muere alegóricamente, es decir, renuncia efectivamente a su provecho («debe ceder / a vuestro bien mi provecho»). La muerte alegórica resulta en gozo efectivo cuando un acto de justicia conjetural o aleatoria se ratifica con él. La epístola da testimonio de esta ocurrencia.

El poeta es un siervo de amor del Señor en tanto su goce depende de él. Sujeto al Señor, trabaja por el goce de otro, que es el goce de su Señor, causa absoluta y objeto imposible de su amor. Trabaja en la redacción de una epístola que da testimonio de la servidumbre. Al testimoniar la servidumbre emite una libranza de pago indirecto, y participará eventualmente de ese pago por un acto de justicia. En su segundo 
movimiento, la epístola testimonia de ese acto de justicia y la concomitante participación en un goce mediado dialécticamente $\mathrm{y}$, por tanto, anticipatorio.

Ese goce, en rigor, escapa como totalidad anticipada. Por eso el discurso avanza hasta cierto punto en el decir, pero concluye con la ocultación: «De aquesto no os digo más, / pues sé, de vuestro talento, / que aunque de esto poco os diga, / sabéis vos lo que hay en esto». Lo que se oculta en el discurso no se le oculta al Señor, ya que éste es el principio cuyo goce se anuncia o anticipa. El Señor in absentia o la Marquesa in presentia nombran a la totalidad, que, sin embargo, escapa al nombre: «Sólo de Sus Excelencias / hay mucho que decir: pero / son Sus Excelencias tales, / que no hay qué decir en estom. Esto, el pronombre empleado en las dos citas, designa lo que se oculta, la totalidad que se sobrentiende y escapa.

La epístola es un discurso suspendido de su destinatario: queda pendiente, diálogo trunco, de una respuesta; queda pendiente, anticipando el gozo de una respuesta, gozo aludido y sobrentendido. El gozo es dicho a medias, mediado en el discurso de un tercero, testigo. La efusión de los esposos resulta mediada en un decir, decir que concierne al tercero o testigo: "Y a mi señor Don Gregorio, / le diréis...» El poeta manda abrazar a Doña Ana y decir a Don Gregorio. La orden de pago o libranza es bífida. La mediación dialéctica de la lengua resulta en un gozo decible, mediatizado, anticipación del goce absoluto inmediato del Señor.

Si el Señor Don Diego, con el primer movimiento del poema, es el objeto ausente del amor, la Virreina, Marquesa de la Laguna, es el objeto presente del amor. Ambos representan el mismo objeto en el decir del poema. Ausencia en el decir, presencia en el decir. Mediación del decir en los dos casos, en los dos movimientos. Jamás la presencia en sí, absoluta, sino siempre la presencia anticipada, mediada dialécticamente. Sin embargo, en el segundo movimiento del poema se cumple una presencia mediada del objeto. En el primer verso del romance no cabe el mío (de Señor mío). Cabe en otros versos del poema. Escribir la epístola es encontrarle lugar al mío suprimido del primer verso. Al final del primer movimiento, el poeta logra insertar dos $m i$ («mi Señora Doña Ana» y «mi Señor Don Gregorio»). Estos personajes están ausentes, del lado de Don Diego, Señor ausente, pero cuando escribe, poco más adelante, «Mi Señora la Marquesa», se trata de un mi referido a un objeto presente. El acto de justicia del Señor (Oidor, Virrey, Radamanto, Eaco y Minos) permite el pasaje en la epístola, de un $m i$ ausente a un $m i$ presente. $M i$ objeto falta, $m i$ objeto llega. 
El pasaje de un término a otro del poema articula sus dos movimientos en el eje o la bisagra de un acto de justicia de otro, el Señor. El poeta controla sólo mediatamente esa instancia con su trabajo de redacción de la epístola que emite una orden de pago indirecto (abrazo de los esposos). El acto de justicia depende de una ley cuya aplicación no obedece al control directo del poeta. Al escribir la epístola, el poeta se somete a una ley real. El provecho, beneficio o contento del poeta son sacrificados a un amor desinteresado por la justicia.

$Y$ aunque no pretende «la baja usura del premio», recibe el contento en otro («en Dios») de un decir contemplativo, o una mediata contemplación de la belleza en la figura de la Marquesa, anticipo de un goce o «Gloria» que sólo se puede concebir como absoluto en el «Cielo» o después de la muerte. La renuncia verdadera del poeta corresponde con su muerte alegórica (según la alegoría del juicio final, o juicio de Radamanto, Eaco y Minos), por lo cual el segundo movimiento del poema, efecto gozoso de un acto de justicia (según una ley que, en tanto real, engendra también el discurso o epístola), corresponde con la contemplación alegórica de la «Gloria» en la belleza de la Marquesa.

Pero el cumplimiento de esa ley real en el discurso no altera el carácter dialéctico de mediación simbólica de éste. Al contrario, la pone en descubierto. De la totalidad que se escapa al sentido, el discurso siempre rescata partes totalizadas tropológicamente a causa de un goce anticipado: «Mi Señora la Marquesa, / aquel divino portento / en que cada parte es un / todo de lo más perfecto...». Precisamente porque hay una mediación tropológica, la totalidad, el objeto, aunque presente, permanece inaccesible: «a cuyas sagradas luces / son, aun los mismos respetos, / Icaros de mejor Sol, / Faetones de más incendios». El respeto reconoce la distancia entre el siervo y la Señora, pero es tanta la distancia en este caso que aun los respetos resultan atrevimientos de Icaros y Faetontes. O bien «mirar con ojos humildes», o bien «frase con que se explica que una cosa está de cumplimiento y ceremonia» (Diccionario de Autoridades), el respeto define la relación entre el poeta y la Marquesa. Las «sagradas luces» de la Marquesa (comparables a los «lucientes / faroles sacros de perenne llama» en la silva $E l$ sueño), resultan alegorizadas como astros inaccesibles para un respeto atrevido.

Por eso, «querérosla copiar, fuera / pretender mi atrevimiento / copiar las flores al Mayo / y las estrellas al Cielo». Aunque accesibles a la mano (las flores) o accesibles a la vista (estrellas), no se puede copiar lo indeterminado de una floración primaveral o de una diseminación estelar.

Según el Timeo de Platón, el cosmos constituye una copia de un mo- 
delo eterno, inaccesible como tal. La floración primaveral y la diseminación estelar obedecen a una ley real o modelo eterno. El discurso no sólo es inadecuado para dar una comprensión de la ley real, sino también de la indeterminación perceptiva o fenoménica. El discurso no puede abarcar la totalidad de la belleza salvo a través de una reducción tropológica del todo, o una totalización de la parte («cada parte es un / todo de lo más perfecto»).

La realidad de un hecho, en sus consecuencias indeterminadas, no puede determinarse adecuadamente desde un punto de vista. E1 poeta, por tanto, carece del juicio que el Señor posee, en tanto figuración de la autoridad o soberana justicia de lo real. El único criterio lícito al poeta es el amor, ya que establece la relación de servicio al Señor, desmonta el mismo criterio que establece, cede el juicio a una instancia que sobrepasa al criterio exclusivo del poeta.

El único criterio válido es el amor, que consiste en la deposición del criterio, reconociendo al objeto amado el poder de decisión. Es así que, por decisión del Señor, se hace presente la Marquesa, en cuerpo y alma, excelencia tanto sensible como intelectual. En ella «tienen, cuerpo y alma, / un tan indeciso pleito, / que de cuál vence, se están / en utrum los argumentos». A la ausencia se contrapone la presencia, pero su accesibilidad o comprensibilidad no es menos problemática: ¿se trata de aprehender a la Marquesa en tanto cuerpo o en tanto alma? La respuesta a esta pregunta queda suspendida (ya que "están / en utrum los argumentos»). El goce de la presencia de la Marquesa, al estar mediado dialécticamente en un decir, no elimina, sino que aviva o despierta un problema. La aprehensión de su belleza plantea un conflicto de facultades: ¿dónde ubicar la mayor excelencia, en el cuerpo o en el alma? A partir de esta pregunta sólo se ahonda el problema. De hecho, sólo puede hablarse de la Marquesa en términos paradójicos, lo cual descubre la insuficiencia de una gramática que no hace jugar la contradicción, y lleva a plantear una nueva gramática: «Una Gramática nueva / es su hermosura y talento, / donde el más se verifica / sin que se suponga el menos». El término positivo, más, implica el negativo, menos. Pero en la Marquesa todo es más, cada parte, cuerpo y alma, su hermosura y talento, totaliza por su cuenta la belleza o el atractivo. Por eso "no hay Lógico que se atreva / a definir cómo, siendo / sólo un término, en él solo / se da relación y exceso». Una lógica que no ponga en juego la contradicción particularizada como mediación del decir, no podrá dar cuenta del problema en la contemplación de la Marquesa. En el más «se da relación», ya que no es decible sino como relación (con el menos). El más, en tanto concierne a la contemplación de la Marquesa, se hace, 
sin embargo, absoluto, o «exceso». Cada parte se totaliza, es decir, suspende su carácter relativo. El tomar la parte por el todo, ya sinécdoque, ya tropo generalizado, trae consigo una relativización del principio de no contradicción. La lógica de los tropos sería una lógica retórica o figural de la contradicción particularizada.

«No hay Lógico que se atreva / [...] / ni yo sé cómo os explique / este enigma...»: con la parte relativa dar cuenta del exceso, del todo que se escapa: he aquí el problema. Una lógica prescriptiva del principio de no contradicción no puede prever la capacidad del goce en el decir. El goce es un enigma, un estado de ánimo, y su irrupción en el decir un efecto de un acto de justicia que corresponde a una instancia soberana. Sólo puede el poeta atestiguar con un decir fiel a la verdad, aunque inexplicable («ni yo sé cómo os explique») de la contemplación gozosa.

En la experiencia del exceso lo relativo del punto de vista equivoca la totalidad con las partes: «sólo entiendo / que aquello parece más, / que se imagina primero». Lo relativo es el imaginar, mientras que el objeto es absoluto. Esta divergencia o inadecuación entre la facultad y el objeto se advierte como un juego permanente de contradicción particularizada que media entre lo limitado de la facultad representativa (imaginación) y lo absoluto del objeto que se le escapa. La facultad es temporal, sucesiva, relativizadora, mientras su objeto es eterno, absoluto, simultáneo.

Según Diótima, en El banquete, lo bello no se agota, no consiste en lo sensible ni tampoco en un discurso o pensamiento. Es bello en tanto sobrepasa o escapa, y a la vez lleva a engendrar, discursos y pensamientos.

Lo bello no es comprensible en su totalidad; la imaginación ofrece al entendimiento vistas parciales, pero esto es todo lo que se puede comprender de la belleza:

Sólo entiendo / que aquello parece más, / que se imagina primero. / Porque como a su beldad / es corto el conocimiento, / para comprehenderla toda / va de concepto en concepto, / y como no puede junta / comprehenderla, sólo aquello / que está entonces ponderando / le parece más perfecto; / pero en volviendo los ojos / a mirar al otro extremo, / vuelve a suspender el juicio, / neutral, el entendimiento.

El proceso de la imaginación (como el de la «fantasía» en la silva $E l$ sueño) es impersonal («lo que se imagina»). Algo se deja ver o imaginar, y algo imagina algo. El yo del poeta sólo interviene en el acto de juzgar («sólo entiendo»). Pero ambas facultades, en definitiva, cumplen un proceso impersonal e indivisible, aunque insuficiente, de conocimien- 
to de la belleza ( a su beldad / es corto el conocimiento»). La ausencia del Señor Don Diego, la presencia de la Marquesa, culminan en la ignorancia ("vuelve a suspender el juicio, / neutral, el entendimiento»). La ausencia muestra la insuficiencia del poeta como carencia, la presencia de la Marquesa muestra la insuficiencia como limitación de las facultades del poeta.

El entendimiento pondera creyendo estar seguro, en cada instancia sucesiva de la contemplación, de su propio juicio («sólo aquello / que está entonces ponderando / le parece más perfecto»). Pero su ponderación en la instancia sucesiva le hace suspender o revocar el juicio anterior («en volviendo los ojos / a mirar al otro extremo / vuelve a suspender el juicio, / neutral, el entendimiento»). El proceso de conocimiento, insuficiente, funciona haciendo jugar, entre instancia e instancia, la contradicción particularizada. El «volver los ojos», la solución de continuidad de cada gesto, de cada instancia, continúa el proceso de conocimiento insuficiente de la belleza ( a su beldad es corto el conocimiento»). Cada instancia del proceso totaliza tropológicamente la parte que está entonces ponderando, pero el proceso no se totaliza en ningún resultado, ya que la culminación del proceso es la ignorancia o la suspensión del juicio. Así, en cada instancia, la totalización tropológica es un cierto engaño, una falsa ponderación que, sin embargo, es verdadera contemplación de la belleza. La belleza no es lo que se aprehende al final, ya que no se puede comprehender. Su extensión no equivale al conjunto de las instancias del proceso. La extensión de la belleza, del exceso, de la totalidad real que escapa al sentido, es una totalidad que cancela el sentido, a la vez que lo impulsa como su finalidad.

El romance epistolar a Don Diego Valverde, diálogo monológico o suspendido, constituye en su trayecto de conceptos gracianescos un proceso cuya ley, en tanto escapa al criterio del poeta, es objeto imposible de su amor. Sus dos movimientos, la alternativa de ausencia y presencia que construye, completan el panorama de insuficiencia del sujeto en relación al efecto gozoso de un decir según justicia. El Señor (Don Diego, Su Excelencia el Virrey) condiciona la verdad del decir del poeta y forma su criterio, dándole una pauta, cuya repetición hace el azar de la lectura. 


\section{EL «ROMANCE» DE SOR JUANA}

Antepone las medras de quien se halla favorecido, al sentimiento de su ausencia, y le da el parabién de su mismo pesar

Señor Don Diego Valverde (y no os parezca despego no decir mío, que fue porque no cupo en el verso, aunque su estrechez ceñida poco embaraza mi afecto, pues lo que no cabe en él sabéis que cabe en mi pecho).

$Y$ supuesto, Señor mío,

10 bien que el serlo no es supuesto, porque siempre que os declino es por meus, mea, meum, vamos a lo principal, aunque por difícil tengo apartarme de un cariño por acercarme a un respeto.

Un pláceme quiero daros; no os admiréis si no acierto a dárosle, porque mal

20 puedo dar lo que no tengo.

Porque ¿qué gusto me pueden causar a mí vuestros puestos, si cuanto os miro más alto tanto estáis de mí más lejos?

Pero por cumplir con ambos, en el pesar y el contento, el parabién os remito y con el pésame quedo.

¿No habéis visto, cuando muere

30 un Monarca, que su Reino hace exequias al Difunto, y fiestas al Heredero, juntando a un tiempo, leal, los dos distantes extremos de aclamaciones del Vivo con los sollozos del Muerto,

en que tan equivocados al pesar y al gusto vemos, que es todo llantos el gusto 
$40 \quad$ y el pesar todo festejos?

Pues así yo, combatida

de tan contrarios afectos

como el gusto que lográis

y la pena de perderos,

en dos mitades del alma

festiva y llorosa a un tiempo, mi muerta esperanza lloro $\mathrm{y}$ vuestras dichas celebro.

Pero, pues debe ceder

50 a vuestro bien mi provecho, aunque deje mi alegría quejoso a mi sentimiento,

venza vuestro bien mi mal, pues conoceréis en esto, que os quiero más para vos de lo que para mí os quiero.

Sed vos feliz, sed dichoso, gozad de honores supremos, aunque sean mis pesares

60 de vuestros gustos el precio.

Carezcan de vos mis ojos, si ha de ser para bien vuestro; que antepone mi fineza el veros feliz, al veros.

Carecer por vos de todo, no hubiera sido en mi afecto fineza, que aun lo insensible lo hace, por irse a su centro.

Pero carecer de vos,

70 atenta a vuestros aumentos, digan si ha sido fineza vuestras prendas y mi aprecio.

Y más, cuando es del partido tan ventajoso el exceso, que tanto más que ganáis viene a ser lo que yo pierdo.

Pues lo que yo pierdo en vos sois vos; y esto presupuesto, multiplicad vuestras medras,

80 que por fuerza serán menos.

¡Qué de cosas os dijera de éstas, Señor! Pero temo que desaliñen las voces lo que pulen los afectos; 
o también, que penséis vos con los encarecimientos, que pretende mi fineza la baja usura del premio.

Pero bien sabéis que son

90 tan nobles mis pensamientos, que pretendo sólo el lauro de que ninguno pretendo.

$Y$ también sabéis, que como es mi amor de entendimiento, no ha menester de la vista materiales alimentos,

pues radicado en el alma, independiente y exento, desprecia de los sentidos

100 el inútil ministerio.

Mucho dista el Sol luciente de la tierra, y no por eso dejan en ella sus rayos de producir sus efectos.

Por más que doblen distancia esos claros once espejos, ¿dejan de imperar los Astros en los sublunares cuerpos?

¿Les pueden a sus influjos

110 ser de algún impedimento las raridades del aire ni los ardores del fuego?

No; luego menos, Señor, podrán impedir quereros, golfos de tierra envidiosos, muros de mar interpuestos, pues mayor que su distancia es, para obrar en mi pecho, la actividad de la Esfera

120 de vuestros merecimientos.

Mas no de esto infiráis que sin vos gustosa estar puedo: que una cosa es el amor y otra cosa es el contento.

Que bien veis que son dos causas muy distintas, y que a un tiempo el amor puede ir a más $y$ el gusto puede ir a menos. 
Y así, vuestra ausencia el alma,

130 con dos distintos respectos,

la ignora, cuanto al olvido,

la sabe, cuanto al tormento.

De aquesto no os digo más, pues sé, de vuestro talento, que aunque de esto poco os diga, sabéis vos lo que hay en esto.

A mi Señora Doña Ana, vuestro digno hermoso empleo, dad de mi parte un abrazo,

140 y cobrádselo en lo mesmo;

que si acepta la libranza, no hay duda que quedaremos, yo $\sin$ la deuda, gustoso vos, $\mathrm{y}$ todos muy contentos.

$\mathrm{Y}$ a mi Señor Don Gregorio, le diréis que en Dios espero verlo Magno, cuando no Taumaturgo Nacianceno.

Las cosas de por acá

150 se están así, que es el Reino malo para Atica, porque no tiene nada de nuevo.

$\mathrm{Y}$ así no hay qué noticiaros, porque es ya todo tan viejo, que el nihil sub sole novum tienen todos en proverbio.

Sólo de Sus Excelencias hay mucho que decir; pero son Sus Excelencias tales, 160 que no hay qué decir en esto.

Tan innato en Su Excelencia es el juzgar bien y recto, que parece que nació a ser Juez, hecho y derecho.

Radamanto con Eaco y Minos, si a su gobierno se comparan, pueden irse a sentenciar al Infierno.

Mi Señora la Marquesa,

170 aquel divino portento en que cada parte es un todo de lo más perfecto, 
a cuyas sagradas luces son, aun los mismos respetos, Icaros de mejor Sol, Faetontes de más incendios, querérosla copiar, fuera pretender mi atrevimiento copiar las flores al Mayo y las estrellas al Cielo:

en quien tienen, cuerpo y alma un tan indeciso pleito, que de cuál vence, se están en utrum los argumentos.

Una Gramática nueva es su hermosura y talento, donde el más se verifica sin que se suponga el menos.

No hay Lógico que se atreva

190 a definir cómo, siendo sólo un término, en él solo se da relación y exceso.

$\mathrm{Ni}$ yo sé cómo os explique este enigma; sólo entiendo que aquello parece más, que se imagina primero.

Porque como a su beldad es corto el conocimiento, para comprehenderla toda

200 va de concepto en concepto, y como no puede junta comprehenderla, sólo aquello que está entonces ponderando le parece más perfecto; pero en volviendo los ojos a mirar al otro extremo, vuelve a suspender el juicio, neutral, el entendimiento.

En fin, por hablar de Gloria,

210 os la nombré a lo postrero; que es pronóstico a mi dicha ser mi fin su hermoso Cielo. 